\title{
Implementation Considerations for the Applied Business Intelligence in Healthcare
}

\author{
Nasim Sadat Mosavi* and Manuel Filipe Santos ${ }^{2}$ \\ 1,2 University of Minho, Guimareas,Portugal, \\ *musavinasimsadategmail.com
}

\begin{abstract}
Whereas it is argued that, implementation of Business Intelligence (BI) systems in healthcare is costly, complex, resource incentive and has been remained as a challenge to undertake [2]. It is important to take into account that implementation of such a system in a knowledge-driven and complex domain like healthcare, not only needs technology infrastructure but also, requires a strategic plan, decision flow, individual interaction, and knowledge management [5]. This study aims to identify and present the most critical factors that should be considered in the BI project management-implementation phase. Besides, theoretical foundations support the finding and discussion.
\end{abstract}

Keywords: Success factors, Healthcare, Business Intelligence, Implementation, Project Management.

\section{Introduction}

Business Intelligence (BI) is a wide term, and many chief information officers ranked it as a high priority for collecting, storing, and analyzing data to support decisionmaking tasks. Whereas, successful implementation of such systems needs integration of diverse resources (e.g., infrastructure, hardware, software, training, licenses, and tools) and management support, yet many companies fail to obtain the perceived value of that [7]. In a complex domain such as healthcare, where the implementation of BI applications requires the ability to deal with the integration of business model and data, the Critical Success Factors (CFFs) that influence the success or failure of BI implementation, are poorly understood [14]. Since the successful implementation of information system projects remains as a major theoretical and managerial challenge [9],this study intends to examine theoretical foundations from the IS domain: Sociotechnical" and "Diffusion of Innovation" (DoI) for discussing influential factors in the success or failure of such systems. 


\section{Information Systems Implementation Considerations and Theories}

The socio-technical theory introduces three influential indicators for successfully implementing an Information System (SI) project. First, the social considerations focus on effective management of people, organizational, and cultural aspects Secondly, the technological aspects that are related to the development and use of suitable technologies. , and the third one, the socio-technical approach in the implementation phase which is about a perfect harmony between the first and second factors; the technological and human-related activities[6,15]. Moreover, the Diffusion of Innovation (DoI) theory also has been adopted in literature to explain factors that associate with the implementation success of IS projects. From the DoI perspective, BI is an innovation to improve the decision making task in an organization [14]. Therefore, not only organizational factors (e.g., management support, organizational culture and objectives, vision individual willingness) affect the successful implementation of BI but also characteristics of BI such as complexity, compatibility, relative benefits should be taken into account. Technical compatibility refers to how well and easy the innovation integrates with existing systems and complexity is about the level at which an innovation is difficult to understand and adopt that may cause user resistance and dissatisfaction. Besides, environmental aspects have shown contribution with IS innovation behaviors [6]. When competitive pressure leads to the adoption of innovation in a firm for developing new technology for accessing competitive opportunities in the marketplace[1].

\section{Examining the Role of "Socio-Tech" and "DoI" Approaches on The Implementation Success of BI Applied in Healthcare}

Introducing new technology into a business not only requires a large financial investment, but also people collaboration, policies, technological and managerial aspects. Whereas projecting BI helps healthcare to perform efficiency, at the same time, the complexity of this domain and how well policies, and technology are adjusting within the industry affect the success of the implementation $[2,6]$. Therefore, a clear vision and organizational mind-set to keep the project in the correct direction are vital $[5,16]$. Figure 1 illustrates some of the most common critical success factors that are used for BI implementation and summarized those influential elements into the four categories: "healthcare characteristics", "BI characteristics", "organizational mind-set" and "environmental pressure" [2].

\subsection{Complexity of Healthcare}


Since the architecture of healthcare service is based on the integration of various delivery models, hence, access to the decentralized ecosystem of data (personal records, of the patient, telehealth, and other healthcare applications based on the patient's home) is a major challenge[2,8]. Moreover, healthcare data is Heterogeneous (e.g., biomedical, operational, clinical, and individual health records) and comes from multiple resources. This feature affects the speed and quality of BI implementation [5], Furthermore, the security and privacy of such data is another important challenge. Hence, in addition to those features which make various layers of complexity in healthcare [3], the poor understanding of industry, less organizational support slow down the implementation of BI [17].

\subsection{Compatibility and Complexity of BI}

Because BI systems include various applications and subsystems (e.g., expert systems, OLAP, data mining tools, predictive analysis, and optimization modules) [13], Therefore, customizing the BI solution according to the existing architecture of business processes affect the speed and quality of implementation. Hence, reengineering the process can be a promising solution to facilitate technological adjustment $[1,10]$. Also, selecting the compatible and suitable solution guarantee smooth technological adjustment and facilitate the required integration [11].

\subsection{Organization Mind-set}

Introducing the new system to people in the organization facilitates the transition phase and a clear understanding of the result of the implementation causes better cooperation [16]. Moreover, change management can overcome staff resistance to change $[4,8,14$, 16]. Besides, management must understand to what extent the BI solution improves the organization to a higher level. Therefore, forming such an organizational mindset before allocating the resources affect a smooth solution development [2]. Furthermore, to highlight the benefits and advantages of the new system and to facilitate the communication between entities during the implementation, proposing a prototype is suggested. Finally, the quality of training sessions offered by the instructor influence the active participation of staff $[14,16]$.

\subsection{Legal Pressure}

The legal indicators which depend on changes in regulation and policies under the responsibilities of government and the network of legal frameworks such as the US Health Insurance Portability and Accountability Act (HIPAA)and the EU General Data Protection Regulation (GDPR) and National Health Insurance (NHI) [8] affect the firm's business process for periodic reengineering [10]. 


\section{Healthcare Characteristics}

(real time data from diverse resources such as intencive care units, decentralized ecosystem of data,complexity and hetrogeniously of data, security and privacy of data, complexity of business processes)

\section{Organizational Mind-Set}

(top management support, Orgonizational culture, vision, objectives, communication)

\section{BI Characteristics}

(complexity, compatibility, easy to learn and underestand)

\section{Environmental Pressures}

(policies, legal and market pressures)

Fig 1. Implementation considerations for the applied BI in healthcare

\section{Discussion}

As we discussed above, the socio-technical theory expresses the harmony of the relationship between the two dimensions (technological aspects and social aspects) for obtaining success in any IS project. Therefore, considering BI as a socio-technical phenomenon, integrating social aspects with technological, via a perfect harmony, results in successful implementation. [12]. Similarly, the DoI approach explains the effective balance between innovation characteristics and organizational elements. In addition to technical and organizational factors, DoI considers the environment's pressure as the third effective dimension too. Therefore, by examining these two theories in a complex domain such as healthcare, the gap of "characteristic of the business domain" is highlighted. The characteristics of the domain show the level of complexity of the workflows, data, interconnected modules, sub-applications, and business processes. Furthermore, the complexity of the nature of the domain demonstrates how easy and smoothly new systems can adapt and communicate with existing systems. Table 1 presents a summary of examining these two paradigms on the Implementation of applied BI in healthcare. Social-technical" and "DoI" theories, both emphasize "Organizational Mind-set" including influential organizational and social elements such as people skills, management support, training strategy, organizational culture, objectives, and vision. These factors in harmony with innovation, characteristic of complexity, and adaptability can provide a successful atmosphere of implementation. Moreover, environmental pressure such as competitive market pressure and legal policies are important for achieving a successful outcome. 
Besides, this study introduces the new indicator, "Domain Characteristics", as a crucial indicator that carries a significant impact on failure or success in implementation. In other words, "healthcare characteristics" which are about the complexity of data and business processes, decentralized and heterogeneity of data, security, privacy, and real time data from diverse resources (e.g., monitors, medical devices in intensive care units) and interconnected sub-applications, should be taken into the account along with other three factors for perusing successful implementation of BI.

Table1. Influential Factors in Project Management-Implementation Phase- Findings

\begin{tabular}{|c|c|c|c|c|c|}
\hline $\begin{array}{c}\text { Domain: Healthcare } \\
\text { Innovation: } \\
\text { B I Applications }\end{array}$ & Indicators & $\begin{array}{c}\text { Theoretical } \\
\text { Considerations }\end{array}$ & 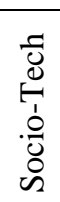 & $\bar{\circ}$ & $\stackrel{\substack{0 \\
:}}{:}$ \\
\hline $\begin{array}{l}\text { Organizational } \\
\text { Mind-Set }\end{array}$ & $\begin{array}{l}\text { Management support, Communication, Training, Vision and Objectives, } \\
\text { Organizational Culture, Change Management }\end{array}$ & $\begin{array}{l}\text { Social and Organizational } \\
\text { Factors }\end{array}$ & $\mathrm{X}$ & $X$ & $X$ \\
\hline $\begin{array}{l}\text { Environmental } \\
\text { Factors }\end{array}$ & Competitive Market Pressure, Legal Pressure & Environmental Factors & $\mathrm{X}$ & $\mathrm{X}$ & $\mathrm{X}$ \\
\hline BI Characteristics & Complexity and Compatibility of Innovation & $\begin{array}{l}\text { Technological Innovation } \\
\text { Consideration }\end{array}$ & $\mathrm{X}$ & $\mathrm{X}$ & $\bar{X}$ \\
\hline $\begin{array}{l}\text { Healthcare } \\
\text { Characteristics }\end{array}$ & $\begin{array}{l}\text { Complex and decentralized data, real time data from various } \\
\text { resources such as intensive care units, the complexity of the business } \\
\text { process, security and privacy of data, heterogeneously of data. }\end{array}$ & Domain Characteristics & $\mathbf{X}$ & $\mathbf{X}$ & $\mathbf{X}$ \\
\hline
\end{tabular}

\section{Conclusion}

This study discussed important considerations about BI implementation in the healthcare domain; two significant theories, socio-technical and diffusion of innovation (DoI) are practiced for identifying and explaining influential factors in the failure or success of BI implementation. Moreover, we concluded that among "Organizational Mindset", "Innovation Characteristics" and "Environmental pressure", understanding the complexity of the domain (healthcare) is crucial to enhance the best possible performance in the implementation phase.

\section{Acknowledgments}

The work has been supported by FCT - Fundação para a Ciência e Tecnologia within the Projects Scope: DSAIPA/DS/0084/2018.

\section{References}

[1] Bradford, M. and Florin, J. 2003. Examining the role of innovation diffusion factors on the implementation success of enterprise resource planning systems. International 
Journal of Accounting Information Systems. 4, 3 (2003), 205-225. DOI:https://doi.org/10.1016/S1467-0895(03)00026-5.

[2] Brooks, P. et al. 2015. A framework for developing a domain specific business intelligence maturity model: Application to healthcare. International Journal of Information Management. 35, 3 (2015), 337-345. DOI:https://doi.org/10.1016/j.ijinfomgt.2015.01.011.

[3] Coelho, D. et al. 2016. Towards of a Business Intelligence Platform to Portuguese Misericórdias. Procedia Computer Science. 100, (2016), 762-767. DOI:https://doi.org/10.1016/j.procs.2016.09.222.

[4] Cooper, R. and Zmud, R. 1990. Information Technology Implementation Research : A Technological Diffusion Approach Author ( s ): Randolph B . Cooper and Robert W . Zmud Published by: INFORMS Stable URL: http://www.jstor.org/stable/2661451 REFERENCES Linked references are available on. Management Science. 36, 2 (1990), 123-139.

[5] Duan, Y. et al. 2019. International Journal of Information Management Artificial intelligence for decision making in the era of Big Data - evolution, challenges and research agenda. International Journal of Information Management. 48, January (2019), 63-71. DOI:https://doi.org/10.1016/j.ijinfomgt.2019.01.021.

[6] Foshay, N. and Kuziemsky, C. 2014. Towards an implementation framework for business intelligence in healthcare. International Journal of Information Management. 34, 1 (2014), 20-27. DOI:https://doi.org/10.1016/j.ijinfomgt.2013.09.003.

[7] Gaardboe, R. et al. 2017. ScienceDirect ScienceDirect Business Intelligence Success applied to Healthcare Information Business Intelligence Success applied to Healthcare Information Systems Systems. Procedia Computer Science. 121, (2017), 483-490. DOI:https://doi.org/10.1016/j.procs.2017.11.065.

[8] Harrer, S. et al. 2019. Artificial Intelligence for Clinical Trial Design. Trends in

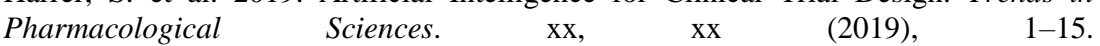
DOI:https://doi.org/10.1016/j.tips.2019.05.005.

[9] Hsinchun Chen,Roger H. L. Chiang, V.C.S. 2018. B Ig D Ata a Nalytics. 36, 4 (2018), 1165-1188. DOI:https://doi.org/10.5121/ijdps.2017.8101.

[10] Kao, H. et al. 2016. Computers in Human Behavior Design and evaluation of hospitalbased business intelligence system ( HBIS ): A foundation for design science research methodology. Computers in Human Behavior. 62, (2016), 495-505. DOI:https://doi.org/10.1016/j.chb.2016.04.021.

[11] Kao, H.Y. et al. 2016. Design and evaluation of hospital-based business intelligence system (HBIS): A foundation for design science research methodology. Computers in Human Behavior. 62, (2016), 495-505. DOI:https://doi.org/10.1016/j.chb.2016.04.021.

[12] Luna-Reyes, L.F. et al. 2005. Information systems development as emergent sociotechnical change: A practice approach. European Journal of Information Systems. 14, 1 (2005), 93-105. DOI:https://doi.org/10.1057/palgrave.ejis.3000524.

[13] Michalewicz, Z. et al. 2006. Adaptive business intelligence.

[14] Puklavec, B. et al. 2018. Understanding the determinants of business intelligence system adoption stages an empirical study of SMEs. Industrial Management and Data Systems. 118, 1 (2018), 236-261. DOI:https://doi.org/10.1108/IMDS-05-2017-0170.

[15] Šajeva, S. 2010. The analysis of key elements of socio-technical knowledge management system. Economics \& Management. 2007 (2010), 765-774.

[16] Ting, S.L. et al. 2011. Critical elements and lessons learnt from the implementation of an RFID-enabled healthcare management system in a medical organization. Journal of Medical Systems. 35, 4 (2011), 657-669. DOI:https://doi.org/10.1007/s10916-0099403-5.

[17] Zheeng, G. et al. 2014. Bringing business intelligence to healthcare informatics curriculum. (2014), 205-210. DOI:https://doi.org/10.1145/2538862.2538935. 